\title{
Effect of Ethanol Ingestion on Thiamine Metabolism: Clinical and Experimental Studies
}

\author{
Toshiki InOKuCHI, ${ }^{1}$ Kikuko Inoue, ${ }^{1}$ Akira Aoyama, ${ }^{2}$ \\ and Naotaka HASHIZUME ${ }^{1}$ \\ ${ }^{1}$ The 2nd Department of Medicine and ${ }^{2}$ The 1st Department of Pathology, \\ Toho University School of Medicine, Ohta-ku, Tokyo 143, Japan
}

(Received October 31, 1980)

\begin{abstract}
Summary The effect of ethanol ingestion on thiamine metabolism was studies both in man and rats, and in the latter, the effect on the central nervous system was also studied morphologically. Fifty alcoholics who had consumed $120 \mathrm{~g}$ of ethanol daily for more than ten years were selected including 7 with delirium tremens. None of them had either Wernicke's encephalopathy or peripheral neuritis. More than half of them had blood thiamine levels within the normal range. With the determination of the hemolysate transketolase (TK) activity and thiamine pyrophosphate (TPP) effect, however, thiamine deficiency was detected in more than half of them and was seen more frequently in the cases with liver damage. All patients with delirium tremens except one had both liver damage and thiamine deficiency. In the animal experiments, when $36 \%$ of the daily total calorie of the thiamine-deficient diet was given as ethanol for 35 days, the thiamine content of the liver and brain was not decreased as much as in the rat which received the same but non-ethanol diet. Although the TK activity of the liver was low, TPP effect was also decreased. It seemed that ethanol had a sparing action on the thiamine deprivation, but impaired the TK activity of the liver through involvement of factors other than thiamine deficiency. Bilateral diapedesis and status spongiosus of the neuropile were seem in the lateral vestibular nucleus of the rat fed on thiamine-deficient and non-ethanol diet. This typical lesion for thiamine deficiency was not seen when ethanol was added. Instead, degenerative changes in both Purkinje cells and Bergmann glia were remarkable. The changes were much more severe when the rats were fed for a longer period of time ( 75 days) with a minimal amount of thiamine added to the diet. When the rats were fed on ethanol and thiamine-replete diet for a longer period of time (135 days), there were most remarkable changes in astroglia in the striatum. It is suggested that the thiamine deficiency could augment
\end{abstract}

${ }^{1}$ 井口利樹, 井上喜久子, ${ }^{2}$ 青山 彰, ${ }^{1}$ 橋詰直孝

Abbreviations used: SGOT, serum glutamic oxaloacetic transaminase; SGPT, serum glutamic pyruvic transaminase. 
the cerebellar lesions induced by ethanol administration, while ethanol administration could decelerate the appearance of the lesions in the vestibular nuclei induced by thiamine deficiency.

Key Words ethanol ingestion, thiamine deficiency, transketolase, TPP effect, alcoholics, experimental Wernicke's encephalopathy, ultrastructure

It is well known that long-term habitual ethanol ingestion frequently causes peripheral polyneuritis and central nervous system disorders such as Wernicke's encephalopathy. Disturbance in thiamine metabolism has been regarded as an important factor causing these conditions. While thiamine deficiency in Japan has manifested itself as beriberi with the main symptoms of peripheral neuropathy, Wernicke's encephalopathy with the main manifestation of disturbance of the central nervous system has been frequently found among habitual ethanol drinkers in Europe and the U.S.A. The reason for this difference is not yet clear. Although insufficient intake(1), defective absorption (2-4), or disturbed activation(5) of thiamine have been thought to be responsible, the exact pathogenesis has not yet been clarified.

Only a few reports on the change in thiamine metabolism in chronic alcoholics are available in Japan. The present clinical study concerns the relationship between thiamine metabolism and chronic alcoholism. Further, experimental animal studies were carried out biochemically and morphologically to clarify the influence of thiamine deficiency and ethanol administration on the central nervous system.

\section{MATERIALS AND METHODS}

\section{Clinical study}

Fifty chronic alcoholics were selected at random from both the National Kurihama Hospital and the 2nd Department of Medicine, Toho University School of Medicine (47 males and 3 females, ranging in age from 38 to 71 years, 48.2 years on average), who had drunk more than $69 \mathrm{~g}$ (about $540 \mathrm{ml}$ of Japanese sake) of ethanol daily for more than 10 years. None of the patients had clinical evidence of metabolic, gastrointestinal, cardiac, or renal disease. All the patients managed to live socially, although they were habitual excessive drinkers. None of them were taking vitamin preparations. As the control group, 20 university students without any abnormalities found on routine physical examinations were selected.

Alcoholics were divided into two groups according to their serum GOT and GPT values. Twenty-five subjects who had SGOT values above $25 \mathrm{mU} / \mathrm{ml}$ and/or SGPT values above $20 \mathrm{mU} / \mathrm{ml}$ were placed in the group with liver damage, and others in the group without liver damage.

In all subjects, blood thiamine levels, transketolase (TK) activity of the red cell hemolysate and thiamine pyrophosphate (TPP) effect were determined. Blood samples were always obtained from the antecubital vein early in the morning during fasting. 
The total thiamine level in blood was measured by the thiochrome method (6). TK activity of red cell hemolysate was measured by the modified Brin's method $(7,8)$. The TPP effect was calculated from the rate of rise in TK activity after addition of TPP in vitro $(7,8)$. The TPP effect was rated as positive only when a rise of more than $15 \%$ in the activity was seen after addition of TPP.

\section{Experimental study}

1. Animals and Diet. Male Wistar rats weighing about $60 \mathrm{~g}$ were housed individually. The rats were divided into four groups of five animals each. Group 1 was fed on a thiamine-sufficient $(6.06 \mu \mathrm{g}$ thiamine $/ \mathrm{ml} / \mathrm{diet})$ diet with control formula, Group 2 on a thiamine-sufficient diet with ethanol formula, Group 3 on a thiamine-deficient diet with control formula and Group 4 on a thiamine-deficient

Table 1. Composition of liquid diet.

\begin{tabular}{|c|c|c|}
\hline & Control formula & Ethanol formula \\
\hline & (g/liter) & (g/liter) \\
\hline Casein (vitamin-free) ${ }^{\mathrm{a}}$ & 41.4 & 41.4 \\
\hline L-Cystine & 0.5 & 0.5 \\
\hline DL-Methionine & 0.3 & 0.3 \\
\hline Maltose-dextrins & 114.0 & 24.4 \\
\hline Vitamin mixture (thiamine-free) $^{\mathbf{b}}$ & 5.0 & 5.0 \\
\hline Ethanol & 0.0 & 50.0 \\
\hline Corn oil & 8.5 & 8.5 \\
\hline Olive oil & 28.4 & 28.4 \\
\hline Ethyl linoleate & 2.7 & 2.7 \\
\hline Salt mixture ${ }^{c}$ & $\begin{array}{c}10.0 \\
\text { (mg/liter) }\end{array}$ & $\begin{array}{c}10.0 \\
\text { (mg/liter) }\end{array}$ \\
\hline Thiamine hydrochloride $\mathrm{d}^{\mathrm{d}}$ & 6.06 & 6.06 \\
\hline \multicolumn{3}{|c|}{ Caloric content } \\
\hline & (cal/liter) & (cal/liter) \\
\hline Protein & 180.19 & 180.19 \\
\hline Fats & 350.06 & 350.06 \\
\hline Carbohydrates & 469.80 & 114.80 \\
\hline Ethanol & 0.00 & 355.00 \\
\hline Total & $1,000.05$ & $1,000.05$ \\
\hline
\end{tabular}

${ }^{a}$ Purchased from Nutritional Biochemicals Corp., Cleveland, Ohio, U.S.A. ${ }^{\mathbf{b}}$ The vitamin mixture contained (mg/liter): riboflavin, 1.250; pyridoxine, 0.725 ; calcium pantothenate, 5.000; niacin, 3.750; choline chloride, 250.000; biotin, 0.025; folic acid, 0.210; inositol, 25.000; menadione, 0.250; cyanocobalamin, 0.005; $p$-aminobenzoic acid, 12.500; retinyl palmitate, 2.000; ergocalciferol, $0.010 ; \alpha$-tocopherol, 30.000. ${ }^{\mathrm{c}}$ The salt mixture contained (g/liter): $\mathrm{Ca}, 13.74 ; \mathrm{Cl}, 10.16 ; \mathrm{Cu}, 0.01 ; \mathrm{I}, 0.06 ; \mathrm{Fe}, 0.46 ; \mathrm{Mg}, 1.00$; $\mathrm{Mn}, 0.12 ; \mathrm{P}, 7.08 ; \mathrm{K}, 14.48 ; \mathrm{Na}, 6.58 ; \mathrm{S}, 1.40 ; \mathrm{Zn}, 0.01{ }^{\mathrm{d}}$ Thiamine was deleted in order to make a thiamine-deficient diet. 
diet with ethanol formula. The former 3 groups were pair-fed with the fourth group. Composition of each liquid diet (9) is shown in Table 1. The daily food intake and body weight of each animal were measured between 5:00 p.m. and 6:00 p.m. These four groups were fed for 35 days and after overnight fasting, the animals were killed for further analysis (subacute experiment).

For a chronicity experiment, to determine the longer effect of thiamine deficiency, another 5 rats, which were fed on the same diet given to group 4, were given $10 \mu \mathrm{g}$ of thiamine per day for the first week. On each subsequent week the daily dose was reduced by $1 \mu \mathrm{g}$ of thiamine (Group 5). The minimal supplement of thiamine was required for testing the longer effect of the deficiency. Another group, fed on a thiamine-sufficient diet with ethanol formula, was fed ad libitum for 135 days (Group 6).

2. Biochemical analysis. At the end of the feeding, all the rats were fasted overnight and killed by decapitation. The brain and liver were removed, and their thiamine levels and the activities of transketolase were assayed by the same method as described above.

3. Histological analysis. The animals were anesthetized with pentobarbital sodium and killed using intracardiac perfusion method. The brain was fixed in situ with transcardiac perfusion of a saline solution of McEven (10) followed by a mixture of $1.5 \%$ formaldehyde and $1.5 \%$ glutalaldehyde in $0.12 \mathrm{M}$ phosphate buffer ( $\mathrm{pH}$ 7.4). The brain stem was sectioned coronally at the level of the VIII cranial nerve. The cerebellum was sectioned sagittally, and the striatum coronally at the level of the putamen and caudate. The thin block was postfixed in $\mathrm{OsO}_{4}$, dehydrated, and embedded in Epon 812. Survey sections ( $1 \mu$ thick) for light microscopy were stained with toluidine blue. The liver was fixed in $10 \%$ neutral formalin. The tissues were stained with hematoxylin and eosin or Sudan III.

\section{RESULTS}

\section{Clinical study}

Daily ethanol intake of the alcoholics ranged from 69 to $220 \mathrm{~g}$, and averaged $119.5 \pm 39.5 \mathrm{~g}$, the total ethanol intake from the beginning ranging from 503.2 to $2,014.5 \mathrm{~kg}(1,142.0 \pm 428.3 \mathrm{~kg})$.

While no diagnosis of beriberi, amblyopia, alcoholic polyneuritis, alcoholic cerebellar degeneration, or Wernicke's encephalopathy was made in any case, a diagnosis of delirium tremens was made in 7 patients.

a) Blood thiamine level. As shown in Fig. 1, in healthy adults the blood thiamine level ranged from 40 to $90 \mathrm{ng} / \mathrm{ml}$ with an average of $69.4 \pm 13.3 \mathrm{ng} / \mathrm{ml}$, and none showed a level below $40 \mathrm{ng} / \mathrm{ml}$. In 50 alcoholics, the level ranged from 16 to 84 $\mathrm{ng} / \mathrm{ml}$, with an average of $51.4 \pm 17.4 \mathrm{ng} / \mathrm{ml}$ in 25 alcoholics with no liver damage, and $55.5 \pm 13.7 \mathrm{ng} / \mathrm{ml}$ in 25 with liver damage. The difference between the control and alcoholics was statistically significant $(p<0.01)$. No difference was noted between the alcoholics with and without liver damage. The level below $40 \mathrm{ng} / \mathrm{ml}$ was 


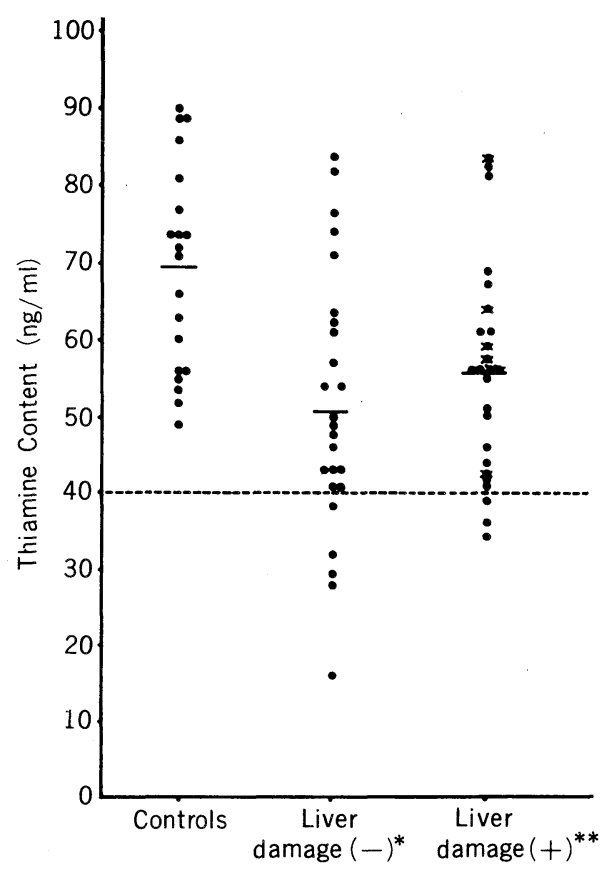

Fig. 1. Blood thiamine level in control subjects and habitual drinkers with and without liver damage. $x=$ Cases with delirium tremens. Difference from the controls ${ }^{*} p<0.01,{ }^{* *} p<0.01$.

seen in only 8 of 50 alcoholics.

b) TK activity in red cell hemolysate. As shown in Fig. 2, TK activity in red cell hemolysate ranged from 730.4 to $1,272.4 \mu \mathrm{g} / \mathrm{ml} / \mathrm{hr}$ in the control group, with an average of $934.2 \pm 172.7 \mu \mathrm{g} / \mathrm{ml} / \mathrm{hr}$.

The value ranged from 282.2 to $1,079.0 \mu \mathrm{g} / \mathrm{ml} / \mathrm{hr}$, with an average of $741.4 \pm 213.5 \mu \mathrm{g} / \mathrm{ml} / \mathrm{hr}$ in alcoholics with no liver damage, and from 207.5 to $1,075.7$ $\mu \mathrm{g} / \mathrm{ml} / \mathrm{hr}$, with an average of $540.6 \pm 244.1 \mu \mathrm{g} / \mathrm{ml} / \mathrm{hr}$ in patients with liver damage, being significantly lower in both than in the control $(p<0.01)$. Patients with liver damage showed significantly lower values than those without liver damage $(p<0.01)$.

A significant positive correlation was noted between blood thiamine levels and TK activity of red cell hemolysate in healthy subjects with $r=0.08426(p<0.01)$. In alcoholics, regardless of the presence or absence of liver damage, there was no significant correlation. Even in 8 subjects with blood thiamine level below $40 \mathrm{ng} / \mathrm{ml}$, no significant correlation was obtained.

c) TPP effect. As shown in Fig. 2, 10 cases $(40 \%)$ of 25 alcoholics without liver damage had TK activity lower than $700 \mu \mathrm{g} / \mathrm{ml} / \mathrm{hr}$, and $6(60 \%)$ of them showed a positive TPP effect. None of the cases who had high TK activity ( $>700 \mu \mathrm{g} / \mathrm{ml} / \mathrm{hr}$ ) had a positive TPP effect. In contrast, 18 cases $(72 \%)$ of 25 alcoholics with liver 


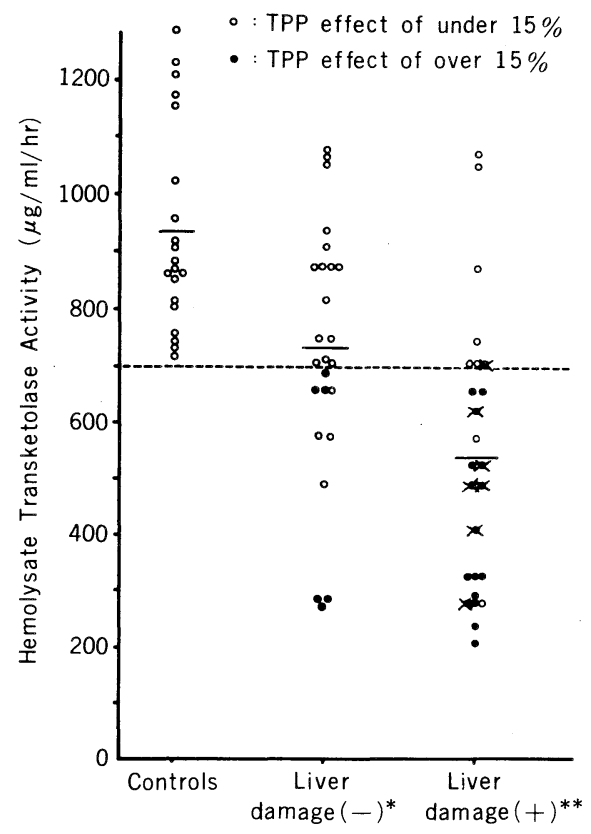

Fig. 2. The hemolysate transketolase activity in controls and habitual alcohol drinkers with and without liver damage. $x=$ Cases with delirium tremens. Difference from the controls ${ }^{*} p<0.01$. Difference from the group without liver damage ${ }^{* *} p<0.01$.

damage had TK activity lower than $700 \mu \mathrm{g} / \mathrm{ml} / \mathrm{hr}$ and 16 of them $(89 \%)$ showed a positive TPP effect.

Figure 3 shows the TPP effect of individual cases, of whom those with values higher than $15 \%$ are TPP positive cases. The rate of positive cases in alcoholics with and without liver damage was $64 \%$ (16/25) and $24 \%(6 / 25)$, respectively.

Regarding the relationship between the blood thiamine level and TPP effect, a positive correlation with $r=0.8660(p<0.01)$ was found in the controls. In alcoholics, on the other hand, there was no significant correlation between them.

d) Patients with delirium tremens. Liver damage was found in all 7 patients with delirium tremens (Figs. 2 and 3). Blood thiamine level ranged from 43 to 83 $\mathrm{ng} / \mathrm{ml}$ and none showed a level below $40 \mathrm{ng} / \mathrm{ml}$. In 6 patients, the TK activity of red cell hemolysate was below $700 \mu \mathrm{g} / \mathrm{ml} / \mathrm{hr}$, and all showed a positive TPP effect. In the remaining patient, TK activity of red cell hemolysate was $705.5 \mu \mathrm{g} / \mathrm{ml} / \mathrm{hr}$, and the TPP effect was $5.9 \%$.

\section{Experimental study}

1. Growth and neurological observations

The growth curves of rats of each group in the subacute experiment and the amount of food consumed are shown in Fig. 4. 


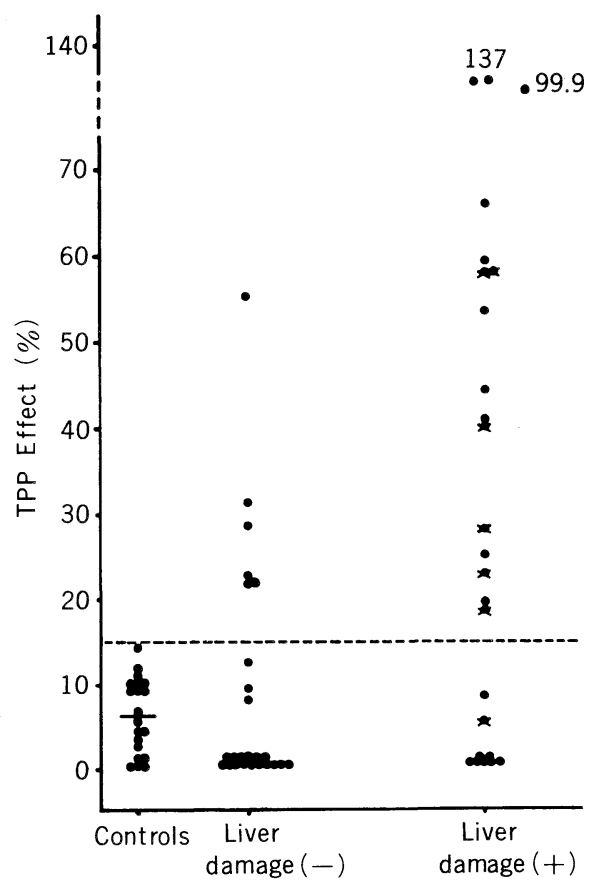

Fig. 3. The per cent TPP effect in controls and habitual alcohol drinkers with and without liver damage. $\times=$ Cases with delirium tremens.

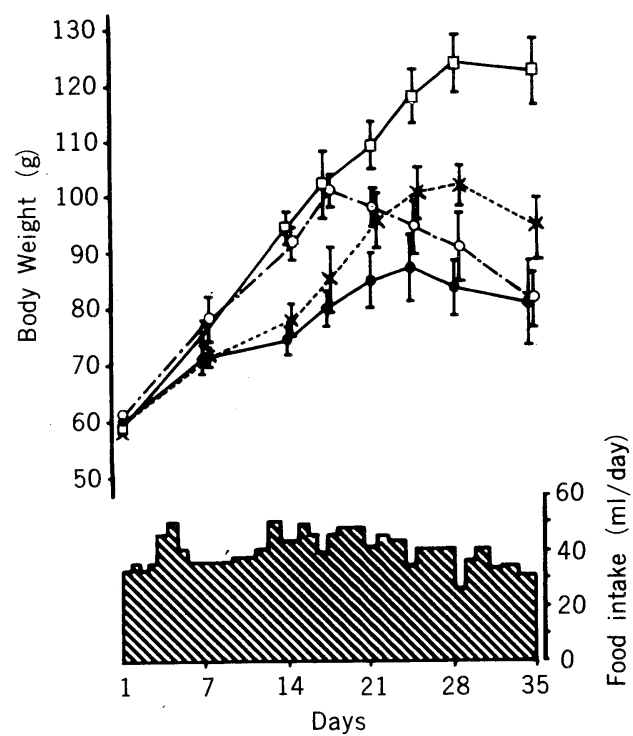

Fig. 4. Growth curves and food intake of the rats fed on a control formula ( $-\square-)$, ethanol formula $(---\times---)$, thiamine-deficient diet with control formula $(--\bigcirc--)$ and thiamine-deficient diet with ethanol formula (-- E - Each plot represented mean \pm SE for 5 rats in each group.

Vol. 27, No. 4, 1981 


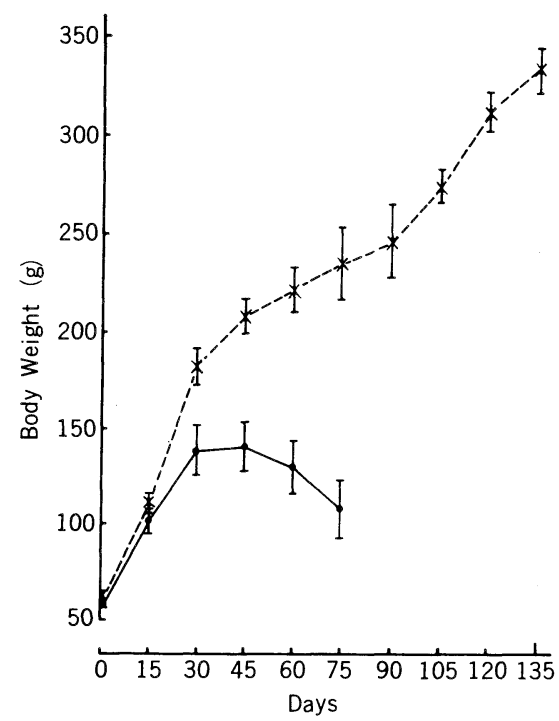

Fig. 5. Growth curves of chronicity experiment. The rats were fed on ethanol formula ad libitum (--- $\times---)$ and received a minimal amount of thiamine in thiaminedeficient diet with ethanol formula (- - -). Each plot represented mean values \pm SE for 5 rats in each group.

The rats on thiamine-replete diet and control formula (group 1) showed a good growth curve, while thiamine-replete diet and ethanol-fed rats (group 2) showed a significantly depressed curve. These two groups remained asymptomatic and appeared healthy throughout the experimental period. The body weights of rats fed on thiamine-deficient diet and control formula (group 3) increased as progressively as those of the controls for the first 18 days of the experiment, but decreased steadily thereafter with a decrease in appetite and activity until day 35 , when the rats suffered from severe disturbances in posture and equilibrium. At this time, rats in group 4 also showed some unsteady gait and frequent abnormal posture with arching of the back.

The terminal average body weight for groups 2, 3 and 4 was significantly lower than that for group $1(p<0.05)$, being lowest in group 4 .

The results for average weight in the other two groups for the chronic experiments (groups 5 and 6) are shown in Fig. 5. After approximately 30 days on thiamine-deficient diet, the average body weight for group 5 stayed on a plateau for 15 days and then decreased progressively. Group 6 showed a satisfactory weight gain. Group 5 showed some unsteadiness of gait on day 75 as observed in group 4 . Group 6 remained asymptomatic.

2. Chemical analysis

1) Thiamine content. Table 2 shows the thiamine contents of the brain and liver, and the grade of fatty degeneration in the liver in each group of the subacute 
Table 2. Thiamine content of brain and liver and degree of fatty liver.

\begin{tabular}{clcccc}
\hline Group & \multicolumn{2}{c}{ Diet } & Brain & $\begin{array}{c}\text { Liver } \\
(\mu \mathrm{g} / 100 \mathrm{~g})\end{array}$ & Fatty degeneration** \\
& Thiamine & Ethanol & $(\mu \mathrm{g} / 100 \mathrm{~g})$ & & \\
\hline 1 & sufficient & - & $413.6 \pm 17.4$ & $1,226.9 \pm 33.5$ & - \\
2 & sufficient & + & $373.2 \pm 32.4$ & $1,141.7 \pm 80.7$ & ++ \\
3 & deficient & - & $101.6 \pm 12.9$ & $116.0 \pm 12.6$ & - \\
4 & deficient & + & $151.4 \pm 16.6^{*}$ & $244.5 \pm 21.9^{*}$ & ++ \\
\hline
\end{tabular}

$\mathrm{M} \pm \mathrm{SE}$ of five rats. ${ }^{*}$ Significant difference $(p<0.001)$ as compared to group 3. ${ }^{* *}$ The degree of fatty degeneration was graded as follows: negative $(-)$, mild $(+)$, moderate $(++)$, and severe $(+++)$.

Table 3. Total thiamine content of the three areas of the brain $(\mu \mathrm{g} / 100 \mathrm{~g})$.

\begin{tabular}{clllll}
\hline \multirow{2}{*}{ Group } & \multicolumn{2}{c}{ Diet } & & & \\
& Thiamine Ethanol & Telencephalon & Brainstem & Cerebellum \\
\hline 1 & sufficient & - & $510.3 \pm 21.3$ & $380.6 \pm 18.8$ & $344.5 \pm 27.4$ \\
2 & sufficient & + & $417.6 \pm 43.0^{*}$ & $351.5 \pm 31.9$ & $351.1 \pm 24.2$ \\
3 & deficient & - & $122.3 \pm 28.4$ & $113.4 \pm 9.7$ & $84.2 \pm 18.6$ \\
4 & deficient & + & $154.5 \pm 23.6^{* *}$ & $150.7 \pm 21.2^{* *}$ & $149.1 \pm 11.3^{* *}$ \\
\hline
\end{tabular}

$\mathrm{M} \pm \mathrm{SE}$ of five rats. $\quad *$ Significant difference $(p<0.001)$ as compared to group 1.

** Significant difference $(p<0.05)$ as compared to group 3.

Table 4. Transketolase activity of liver.

\begin{tabular}{|c|c|c|c|c|c|}
\hline \multirow{3}{*}{ Group } & \multirow{2}{*}{\multicolumn{2}{|c|}{ Diet }} & \multicolumn{2}{|c|}{ In vitro addition } & \multirow{3}{*}{$\begin{array}{c}\text { TPP effect } \\
(\mathrm{B}-\mathrm{A} / \mathrm{A} \times 100) \\
(\%)\end{array}$} \\
\hline & & & \multirow{2}{*}{\multicolumn{2}{|c|}{$\begin{array}{c}\text { Thiamine } \\
\text { None (A) } \quad \text { pyrophosphate (B) } \\
\text { (mg of sedoheptulose- } 7 \text {-phosphate } \\
\text { produced } / \mathrm{g} \text { wet } \mathrm{wt} / \mathrm{hr} \text { ) }\end{array}$}} & \\
\hline & Thiamine & Ethanol & & & \\
\hline 1 & sufficient & - & $68.87 \pm 2.67$ & $68.87 \pm 2.67$ & 0 \\
\hline 2 & sufficient & + & $60.27 \pm 2.89$ & $60.27 \pm 2.89$ & 0 \\
\hline 3 & deficient & - & $22.20 \pm 1.26$ & $35.02 \pm 1.88$ & $57.92 \pm 6.04$ \\
\hline 4 & deficient & + & $17.45 \pm 0.97^{*}$ & $23.87 \pm 1.48^{*}$ & $36.75 \pm 0.96^{*}$ \\
\hline
\end{tabular}

Values represent $\mathrm{M} \pm \mathrm{SE}$ of five rats. * Significant difference $(p<0.01)$ as compared to the values of group 3 .

experiment.

The thiamine contents of the brain and liver were significantly lower in thiamine-deficient groups (groups 3 and 4) than in thiamine-replete groups (groups 1 and 2). However, there was no difference between groups 1 and 2. In thiamine- 
deficient groups, in contrast, thiamine content was significantly lower in group 3 than in group 4.

Table 3 shows the thiamine contents of the three different areas of the brain. A higher concentration was seen in the telencephalon than in the other two areas. The ethanol-fed group (group 2) showed a lower concentration than the non-ethanol fed group (group 1) in this area. However, in thiamine-deficient rats, the ethanol-fed group (group 4) showed a significantly higher concentration than the non-ethanol fed group (group 3) in all three areas.

The thiamine contents of the brain and liver in group 5 were $148.7 \mu \mathrm{g} / 100 \mathrm{~g}$ (average of 3 rats) and $273.7 \mu \mathrm{g} / 100 \mathrm{~g}$ (average of 3 rats), respectively.

2) TK activity. Table 4 shows the TK activity and TPP effect of the liver of each group. TK activity in liver decreased in thiamine-deficient groups (groups 3 and 4) as compared to thiamine-replete groups (groups 1 and 2). Although group 4 had a higher concentration of thiamine in the liver, the TK activity in this organ was lower in this group than in group 3. However, the TPP effect of this group was lower than that of group 3. The brain TK activity was not affected significantly in any group.

Fig. 6. Histological changes in the lateral vestibular nucleus of a rat of Group 3 fed on a thiamine-deficient, non-ethanol diet for 35 days. A focus of perivascular hemorrhage and severe status spongiosus of the neuropile are seen. Semithin Epon Section, Toluidine blue stain. $\times 100$

Fig. 7. Sagittal section of the anterior-superior vermis of a rat of Group 5 fed on a thiamine-deficient and ethanol diet for 75 days. Some Purkinje cells are atrophic. Lightly-staining nuclei and cytoplasm of Bergmann astroglia are prominent (arrow). Semithin Epon Section. Toluidine blue stain. $\times 400$

Fig. 8. Electronmicrograph from the area shown in Fig. 7. Showing atrophic dark Purkinje cells (PC) and marked swelling of Bergmann astrocytes $(\mathrm{Bg}) . \quad \times 1,200$

Fig. 9. A Purkinje cell in a rat of Group 5, fed on a thiamine-deficient and ethanol diet for 75 days. The cytoplasm is filled with faintly visible minute granules and many lamellar bodies (arrow). The cisternae of the Golgi apparatus are ring-shaped (arrow head). $\quad \times 12,000$

Fig. 10. Cerebellar molecular layer in a rat of Group 5. Bergmann glial processes running perpendicularly to the pia mater through the molecular layer are swollen (arrow). $\times 3,000$

Fig. 11. Striatum of a rat fed on a thiamine-sufficient, ethanol diet for 135 days (Group 6). Alzheimer type II astrocytes are seen around a blood capillary (arrow), a: Alzheimer type II astrocytes surrounding a capillary. JB-4 Epon-embedded, H-E stain. $\times 400$

Fig. 12. Perivascular astrocytes in the striatum of a rat of Group 6. The cytoplasm is swollen and edematous. $\times 6,000$

Fig. 13. Chromatolytic large neuron in the striatum of a rat of Group 6. An irregular nucleus is close to the cell border. Rough-ER is concentrated in the cell periphery. In the central portion of the perikaryon, some bizarre-shaped structures are encountered in mitochondria (arrow). $\times 2,400$ 


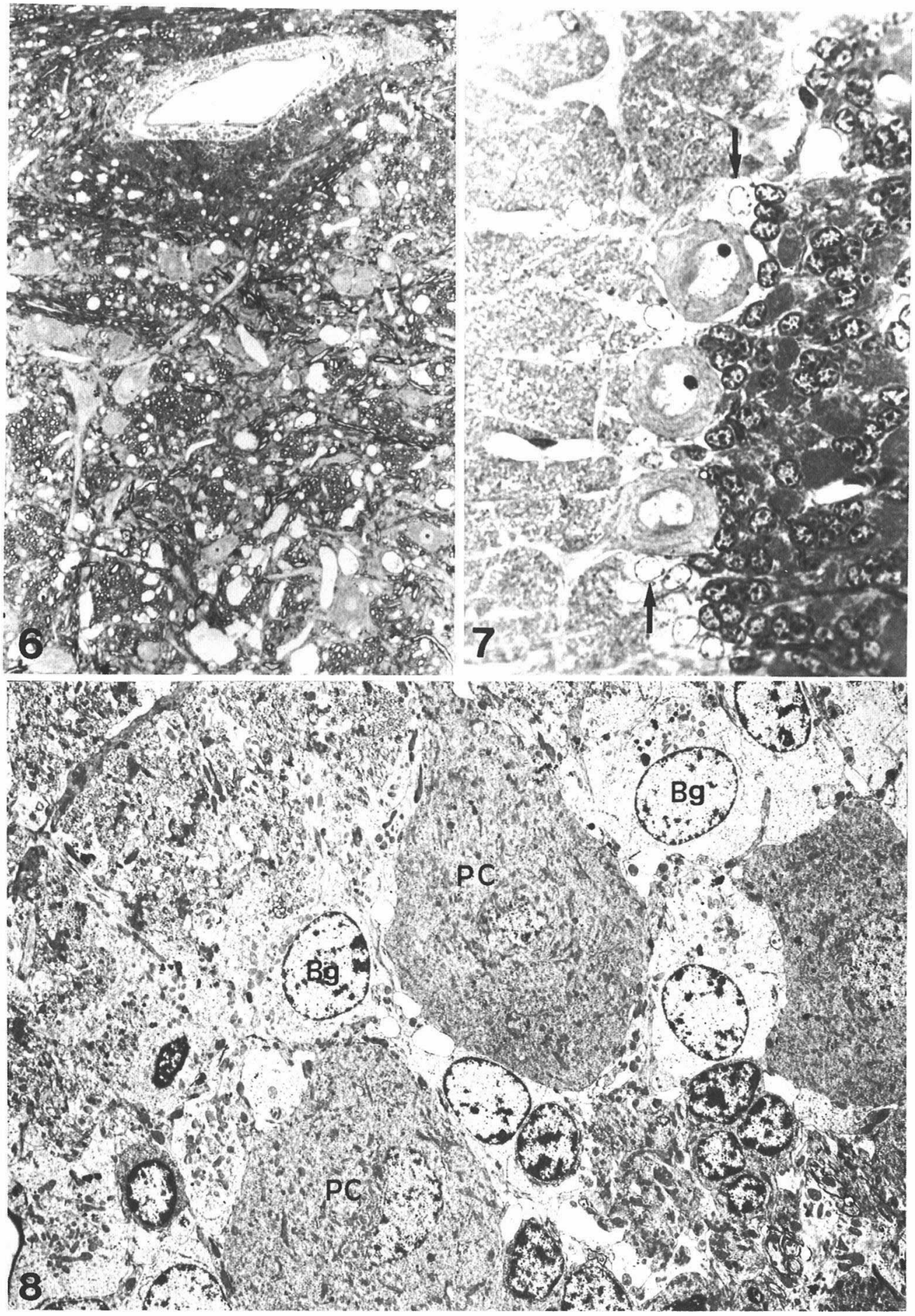

Vol. 27, No. 4, 198 

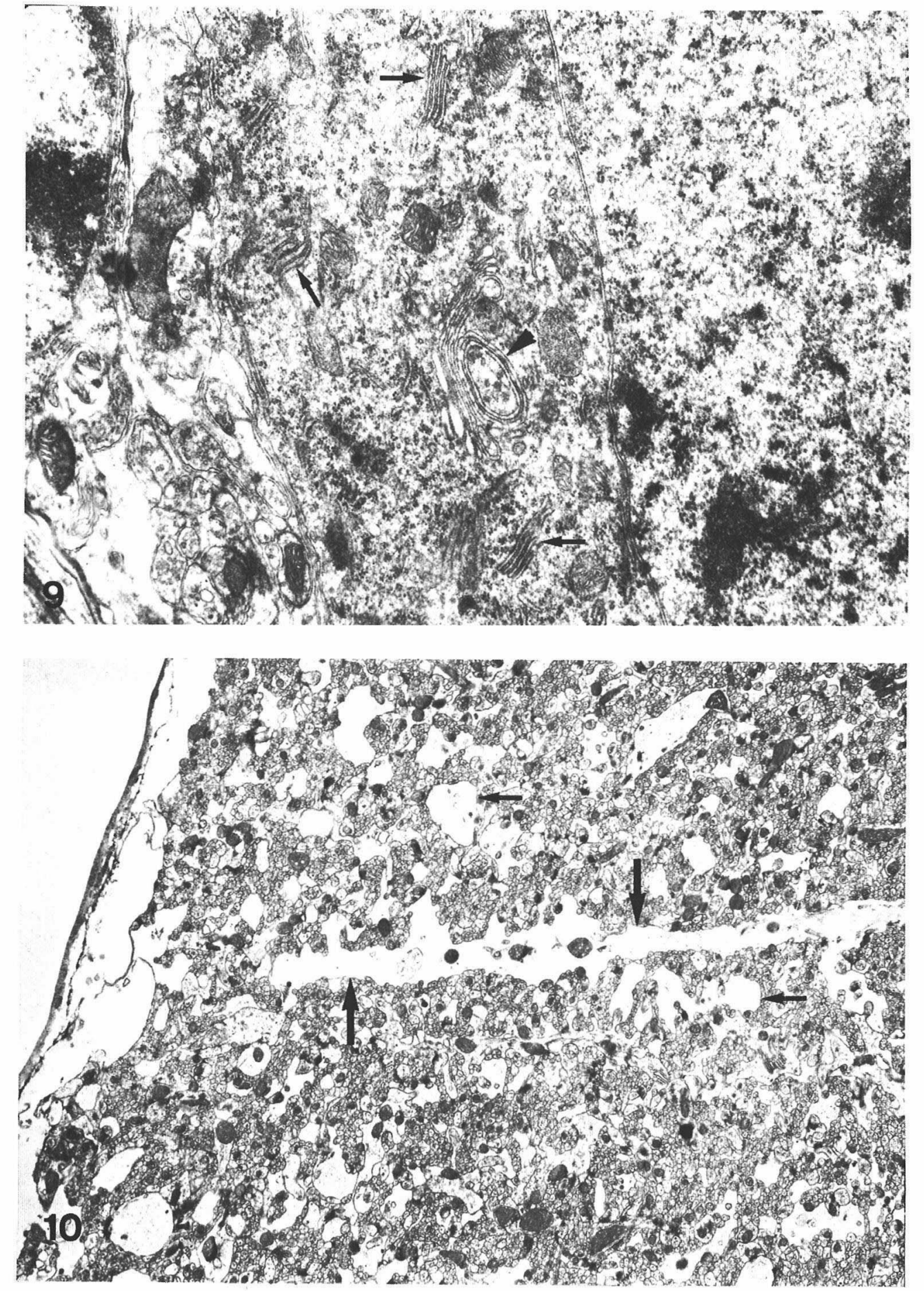

J. Nutr. Sci. Vitaminol. 

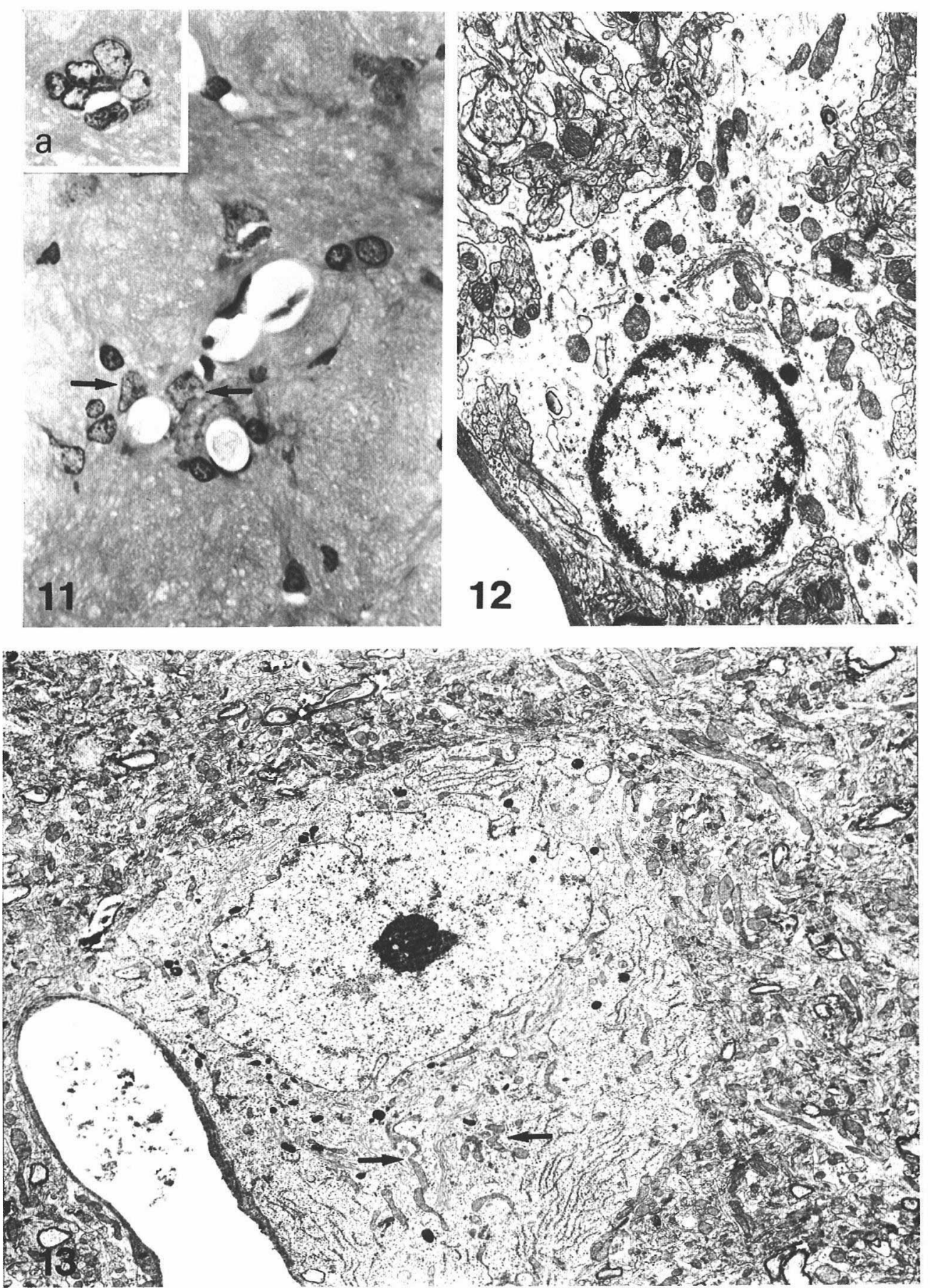

Vol. 27, No. 4, 1981 


\section{Histological studies}

The microscopic features reported here are based on 5 rats selected from each group. They were killed on days 35, 75 and 135 of the experiments. The vestibular nuclei, cerebellum, and striatum (caudate nucleus and putamen) were studied by light and electron microscopy.

2) Thiamine-deficient, and non-ethanol fed rats (group 3). The lateral and superior vestibular nuclei were invariably involved. There was bilateral symmetrical small hemorrhage in all animals killed at the initial stage of tonic seizures.

By light microscopy, the lesions were characterized by severe status spongiosus of the neuropile, and petechial hemorrhage (Fig. 6). No abnormal lesion was found in the cerebellum and striatum.

2) Thiamine-deficient, and ethanol-fed rats in the subacute (group 4) and chronicity (group 5) experiments. There was no difference between the two experiments in terms of clinical symptoms and signs.

There were no gross and microscopic alterations in the vicinity of the vestibular area. Lesions were observed in the cerebellum, caudate nucleus and putamen. The animals in the chronicity experiment showed more severe pathological changes than did those in the subacute group, although there was no essential difference between the two groups in terms of the nature of the changes.

Cerebellum. There were striking changes in the Purkinje cell layer, especially in the vermis. Most of the Purkinje cells were atrophic and showed dark cytoplasm and dendrites. No Nissle substance was present. The Bergmann astrocytes surrounding the shrunken Purkinje cells were increased in number and had extensively swollen cytoplasm (Fig. 7).

At the ultrastructural level the expanded cytoplasmic space of the Bergmann glia showed finely reticular profile containing a small amount of rough-surfaced endoplasmic reticulum (r-ER) and ribosomes, while the mitochondria were relatively well preserved. The nuclear chromatin was clumped along the nuclear envelope (Fig. 8).

Numerous lamellar bodies were formed in the cytoplasm of the Purkinje cells instead of a reduction in the amount of $\mathrm{r}$-ER. The ribosomes were scattered either freely or as polysomes in the cytoplasmic matrix. Another characteristic feature of Purkinje cells included a ring-shaped Golgi apparatus. The nuclei had an irregular nuclear membrane and clumped chromatin with rarefaction of the interchromatin spaces (Fig. 9). Dendritic processes were surrounded by edematous astrocytic processes.

In the molecular layer the Bergmann glial processes were electron-lucent and swollen, being more swollen at the ends near the pial surface (Fig. 10).

Striatum. There was some swelling of both cytoplasm and nucleus of the astrocytes. The neurons showed no significant changes.

3) Thiamine-replete, and ethanol-fed rats in the chronicity experiment (group 6)

Cerebellum. The changes in cerebellum were not so severe as those observed in 
Table 5. Distribution and severity of histopathological changes.

\begin{tabular}{|c|c|c|c|c|c|c|c|c|}
\hline \multirow{2}{*}{ Group } & \multirow{2}{*}{$\begin{array}{r}\text { Di } \\
\text { Thiamine }\end{array}$} & \multirow{2}{*}{ et Ethanol } & \multirow{2}{*}{$\begin{array}{l}\text { Experimental } \\
\text { period }\end{array}$} & \multirow{2}{*}{$\begin{array}{l}\text { Vestibular } \\
\text { nucleus } \\
\text { area }\end{array}$} & \multirow{2}{*}{\multicolumn{2}{|c|}{$\begin{array}{c}\text { Cerebellum } \\
\text { Purkinje Bergmann } \\
\text { cell }\end{array}$}} & \multicolumn{2}{|c|}{$\begin{array}{l}\text { Corpus } \\
\text { striatum }\end{array}$} \\
\hline & & & & & & & $\begin{array}{l}\text { Large } \\
\text { neuron }\end{array}$ & $\begin{array}{l}\text { Astro- } \\
\text { glia }\end{array}$ \\
\hline 1 & + & - & $\begin{array}{r}35 \text { days } \\
75 \text { days } \\
135 \text { days }\end{array}$ & - & - & - & - & - \\
\hline 6 & + & + & 135 days & - & ++ & ++ & + & ++ \\
\hline 3 & - & - & 35 days & $\begin{array}{c}+++ \\
\text { (Spongy } \\
\text { state) }\end{array}$ & - & - & - & - \\
\hline 4 and 5 & - & + & $\begin{array}{l}35 \text { days } \\
75 \text { days }\end{array}$ & - & +++ & +++ & - & + \\
\hline
\end{tabular}

The severity of the neuronal and glial changes was graded as follows: negative ( - ), mild $(+)$, moderate $(++)$, and severe $(+++)$.

thiamine-deficient ethanol groups (groups 4 and 5). The Purkinje cells were shrunken and atrophic, particularly in the antero-superior vermis. The Bergmann glia was slightly swollen and pale.

Striatum. This was the most heavily involved structure in this group. Alzheimer Type II astrocytes were observed in the perivascular area (Fig. 11).

Most astrocytes became hypertrophic, with greatly expanded cytoplasm and broad processes extending into the adjacent neuropile (Fig. 12).

The neuronal changes were characterized light microscopically by the presence of central chromatolysis and ultrastructurally by the paucity of r-ER and free ribosomes in the periphery of the cytoplasm (Fig. 13). There were no abnormalities in the blood vessels. The vestibular nuclei were not remarkable.

Table 5 summarizes the major histopathological findings. There was good correlation between the severity of clinical manifestations and the degree of morphological changes. The areas of vestibular nucleus were most heavily involved in rats in the subacute thiamine-deficient experiment (group 3). They were characterized by necrosis of the neuropile often accompanied by hemorrhage. On the other hand, the cerebellar cortex was most heavily involved in the animals in the chronic thiamine-deficient experiments (group 5). It was characterized by central chromatolysis of Purkinje cells and degenerative changes of Bergmann glia. Changes in the region of the corpus striatum were more pronounced in the animals on chronic ethanol administration (group 6) than in any other groups, being mainly characterized by the appearance of Alzheimer Type II astrocytes and mild chromatolysis of the large neuron. 


\section{DISCUSSION}

The amount of ethanol consumed by the subjects selected for the present study was $120 \mathrm{~g}$ daily over more than ten years, which is the amount well known to cause the development of a variety of pathologies (11). Nevertheless, the major complication was liver injury, which was seen in half of the cases, and no neurological manifestations such as Wernicke's encephalopathy or peripheral neuritis were found in the present series, although seven cases of delirium tremens were included in the alcoholics with liver injury.

Therefore, the condition of the subjects of the present study seemed to be unrelated to thiamine deficiency which is known as an important factor causing neurological pathologies in alcoholics. Although the blood thiamine levels of the subjects were lower than those of the control on the average, more than half of the subjects had the levels within the normal range, and no difference was seen between the cases without liver damage and those with liver damage. Moreover, in all cases of delirium tremens, the levels were higher than $40 \mathrm{ng} / \mathrm{ml}$.

However, as has been pointed out by many workers $(7,12,13)$, the blood thiamine level does not necessarily reflect the deficient state of thiamine, or the presence of disturbed thiamine metabolism in the body. The methods introduced by Brin and his associates (7) for detecting subclinical cases of thiamine deficiency have been tested in many aspects in our laboratory (14-16), and have been proven valuable for clinical use.

In the present study, more than half of the alcoholics had TK activity below the lower limit of the controls, and the mean value of TK activity of the alcoholics with liver damage was significantly lower than that of the controls and the alcoholics without liver damage. Moreover, all patients with delirium tremens had values lower than $705.5 \mu \mathrm{g} / \mathrm{ml} / \mathrm{hr}$.

Regarding the TPP effect, or the rate of increase in TK activity with the addition of TPP, it was positive (more than $15 \%$ increase) only when the TK activity of the hemolysate was lower than $705.5 \mu \mathrm{g} / \mathrm{ml} / \mathrm{hr}$. It was positive in $82 \%$ of the patients who had TK activity lower than $700 \mu \mathrm{g} / \mathrm{ml} / \mathrm{hr}$, the incidence being higher in the patients with liver damage. These results indicate that many alcoholic patients suffered from the thiamine-deficient state, especially in the presence of liver damage.

Delirium tremens was present exclusively in the patients with liver damage, and all but one patient with delirium tremens had low TK activity and a positive TPP effect, despite the blood thiamine levels not being low. These results suggest that delirium tremens is intimately related to liver injury and thiamine deficiency, and that the blood thiamine level is not a reliable indicator for detection of the thiaminedeficient state.

In the animal experiment, however, ethanol administration did not lower the thiamine content of the liver and brain, although it caused fatty degeneration in the liver. In the rats on thiamine-deficient diet, in contrast to other reports $(17,18)$ suggesting that ethanol accelerated thiamine deficiency, ethanol seemed to de- 
celerate the deprivation of thiamine in the brain and liver. This would be reasonable considering that the carbohydrate content of the diet ingested by the ethanol-fed group was only $20 \%$ of that of the thiamine-deficient and non-ethanol fed group.

Although the TK activity of the liver was lower in the ethanol-fed group than in the non-ethanol fed group, the TPP effect was higher in the non-ethanol fed group. These findings suggest that TK activity impairing factors other than thiamine deficiency might be concerned. In this regard, Abe and Itokawa (19) pointed out the importance of the action of acetaldehyde inhibiting TK activity. However, further studies are necessary to elucidate the mechanisms involved.

Furthermore, our results from thiamine-replete and ethanol-fed rats do not exclude the possibility of minor degrees of thiamine malutilization, which could have been masked by the high (more than $200 \mu \mathrm{g}$ per day) dose of thiamine given in the present study. The high doses of thiamine in turn may have prevented thiamine deficiency and may also have induced apoenzyme synthesis (20).

The pathological lesions in thiamine-deficient and non-ethanol fed rats were localized in the region of the vestibular nuclei, as pointed out by other investigators $(21-23)$.

Despite a marked decrease in the thiamine content of the cerebellum, there was no morphological change in the cerebellum in the present study, as opposed to the results reported by Collins and Converse (24). The cerebellar changes in animals on thiamine-deficient and ethanol diet were distinctly different in nature from those in animals on thiamine-deficient diet alone. Some consider them to be artifacts (25), but we presume them to represent changes occurring in reaction to some metabolic derangements in view of overall morphological changes of Purkinje cells, while the significance of the lamellar bodies in the Purkinje cells remains unknown(26). Jarlstedt and Hultborn (27) indicated that chronic ethanol administration caused a decrease in the RNA content of the Purkinje cells. Miyakawa et al. (28) reported cerebellar changes similar to those in our experiment in rats given ethanol for a long period of time. Therefore, the changes in Purkinje cells seem to be a direct effect of ethanol or its metabolites.

The severity of cerebellar changes was correlated directly to the amount of ethanol consumption. This may be partly supported by the increased vulnerability of glia during thiamine deficiency $(29,30)$, but the synergistic effect of ethanol seems to be necessary to build up the changes in the glia and neurons. Although glia is considered to have an important metabolic function interacting with neurons, whether the changes of Bergmann glia represent reactive changes secondary to the Purkinje cell dysfunction or are ascribable to the direct toxic actions of ethanol and/or its metabolites remains unanswered in the present study.

In animals in which ethanol was administered for a long period of time, there were striking astroglial changes in the corpus striatum as compared with animals of other groups. Although it is difficult to conclude that such changes are the direct effect of ethanol or its metabolites, they seemed unrelated to thiamine deficiency in view of the findings in groups 3 and 4 . The changes of the large neuron seemed to be 
associated with the changes in the glia.

There were no findings in the present study indicative of a repairing process as described in Man with Wernicke's encephalopathy. Watanabe and Kanabe (31) pointed out that the tissue reaction in human Wernicke's encephalopathy could possibly be augmented by therapeutic thiamine administration. The reason for the lack of such chronic reactive changes in the present experiment seemed to be that the changes observed were purely the effects of either thiamine deficiency or ethanol administration or both, although the influence of nicotinic acid deficiency which might have occurred should also be taken into consideration.

The changes in the vestibular nuclei observed in animals on pure thiaminedeficient diet could not be reproduced when ethanol was administered. On the other hand, the cerebellar changes in animals on thiamine-deficient and ethanol diet could be considered primarily as ethanol-related changes, which were accelerated by thiamine deficiency. Thus, the present study strongly suggests that ethanol could play the most important part in the morphogenesis of the cerebellar changes and that thiamine deficiency augments them.

The authors wish to express their gratitude to Professor Dr. T. Abe and Professor Dr. T. Abei, The 2nd Department of Medicine, and Professor Dr. N. Fukunaga and Dr. M. Kudo, The 1st Department of Pathology, for their support and helpful advice on this work.

\section{REFERENCES}

1) Neville, J. N., Eagles, J. A., Samson, G., and Olson, R. E. (1968): Nutritional status of alcoholics. Am. J. Clin. Nutr., 21, 1329-1340.

2) Tomaslo, P. A., Kater, R. M., and Iber, F. L. (1968): Impairment of thiamine absorption in alcoholism. Am. J. Clin. Nutr., 21, 1341-1344.

3) Thomson, A. D., Baker, H., and Leevy, C. M. (1970): Patterns of ${ }^{35}$ S-thiamine hydrochloride absorption in the malnourished alcoholic patient. J. Lab. Clin. Med., 76, 34-45.

4) Hoyumpa, A. M., Nichols, S. G., Wilson, F. A., and Schenker, S. (1977): Effect of ethanol on intestinal $(\mathrm{Na}, \mathrm{K})$ ATPase and intestinal thiamine transport in rats. J. Lab. Clin. Med., 90, 1086-1095.

5) Leevy, C. M., and Baker, H. (1968): Vitamins and Alcoholism. Am. J. Clin. Nutr., 21, 1325-1328.

6) Fujiwara, M., and Matsui, K. (1953): Determination of thiamine by the thiochrome reaction; application of cyanogen bromide in place of potassium ferricyanide. Anal. Chem., 25, 810-812.

7) Brin, M., Tai, M., Ostachever, A. S., and Kalinsky, H. (1960): The effect of thiamine deficiency on the activity of erythrocyte hemolysate transketolase. J. Nutr., 71, 273-281.

8) Dische, Z. (1953): Qualitative and quantitative colorimetric determination of heptoses. J. Biol. Chem., 204, 983-997.

9) Decarli, L. M., and Lieber, C. S. (1967): Fatty liver in the rat after prolonged intake of ethanol with a nutritionally adequate new liquid diet. J. Nutr., 91, 331-336.

10) McEven, L. M. (1956): The effect on the isolated rabbit heart of vagal stimulation and its modification by cocain, hexamethonium and ouabain. J. Physiol., 131, 678-689. 
11) de Lint, J., and Schmidt, W. (1971): The epidemiology of alcoholism, in Biological Basis of Alcoholism, ed. by Israel, Y. and Mardones, J., Wiley-Interscience, pp. 423-442.

12) Somogyi, J. C. (1976): Early signs of thiamine deficiency. J. Nutr. Sci. Vitaminol., 22 (Suppl.), 29-32.

13) Hötzel, D., and Bitsch, R. (1976): Thiamine status of human subjects, estimated by biochemical methods. J. Nutr. Sci. Vitaminol., 22 (Suppl.), 41-45.

14) Okada, T. (1967): Studies on transketolase (I). Thiamine and transketolase activity. Vitamins (in Japanese), 35, 279-289.

15) Okada, T. (1967): Studies on transketolase (II). Hepatic transketolase activity in experimental liver injury of rat. Vitamins (in Japanese), 35, 290-294.

16) Hashizume, N., Inokuchi, T., Miyoshi, K., Hanue, T., Inoue, K., Okada, T., Isogai, S., and Hirata, K. (1976): Alcoholic beriberi heart disease. Vitamins (in Japanese), 50, $71-76$.

17) Abe, T., Okamoto, E., and Itokawa, Y. (1979): Biochemical and histological studies on thiamine-deficient and ethanol-fed rats. J. Nutr. Sci. Vitaminol., 25, 375-383.

18) Baker, H., Frank, O., Ziffer, H., Goldfarb, S., Leevy, C. M., and Sabotka, H. (1964): Effect of hepatic disease on liver B-complex vitamin titers. Am. J. Clin. Nutr., 14, 1-6.

19) Abe, T., and Itokawa, Y. (1977): Effect of ethanol administration on thiamine metabolism and transketolase activity in rats. J. Vitam. Nutr. Res., 47, 307-314.

20) Rossouw, J. E., Labadarios, D., Krasner, N., Williams, R. (1978): Red blood cell transketolase activity and the effect of thiamine supplementation in patients with chronic liver disease. Scand. J. Gastroent., 13, 133-138.

21) Tellez, I., and Terry, R. D. (1968): Fine structure of the early changes in the vestibular nuclei of the thiamine-deficient rat. Am. J. Path., 52, 777-794.

22) Robertson, D. M., Wasan, S. M., and Skinner, D. B. (1968): Ultrastructual features of early brain stem lesions of thiamine-deficient rats. Am. J. Path., 52, 1081-1097.

23) Hanue, T., and Hashizume, N. (1979): Influence of thiamine deficiency on central nervous system. Vitamins (in Japanese), 53, 505-512.

24) Collins, G. H., and Converse, W. L. (1970): Cerebellar degeneration in thiaminedeficient rats. Am. J. Path., 58, 219-233.

25) Herndon, R. M. (1964): Lamellar bodies, an unusual arrangement of the granular endoplasmic reticulum. J. Cell. Biol., 20, 338-342.

26) Mato, M., and Uchiyama, Y. (1974): Appearance of lamellar structures in the Purkinje cells of rat cerebellum after administration of $\beta$-amino-propionitrile. Experientia, 30, 1030-1032.

27) Jarlstedt, J., and Hultborn, R. (1972): Experimental alcoholism in rats; RNA content and composition in isolated cerebellar Purkinje cells after long term treatment. $J$. Neuropath. Exp. Neurol., 31, 346-351.

28) Miyakawa, T., Sumiyoshi, S., Deshimaru, M., Hattori, E., and Shikai, I. (1977): Mechanism of histopathological changes of nerve cells experimentally induced by chronic alcohol poisoning. Folia Psychiat. Neurol. Jpn., 31, 263-268.

29) Collins, G. H. (1967): Glial cell changes in the brainstem of thiamine-deficient rats. Am. J. Path., 50, 791-817.

30) Volpe, J. J., and Marasa, J. C. (1978): A role for thiamine in the regulation of fatty acid and cholesterol biosynthesis in cultured cells of neural origin. J. Neurochem., 30, 975-981.

31) Watanabe, I., and Kanabe, S. (1978): Early edematous lesion of pyrithiamine induced acute thiamine deficient encephalopathy in the mouse. J. Neuropath. Exp. Neurol., 37, 401-413. 